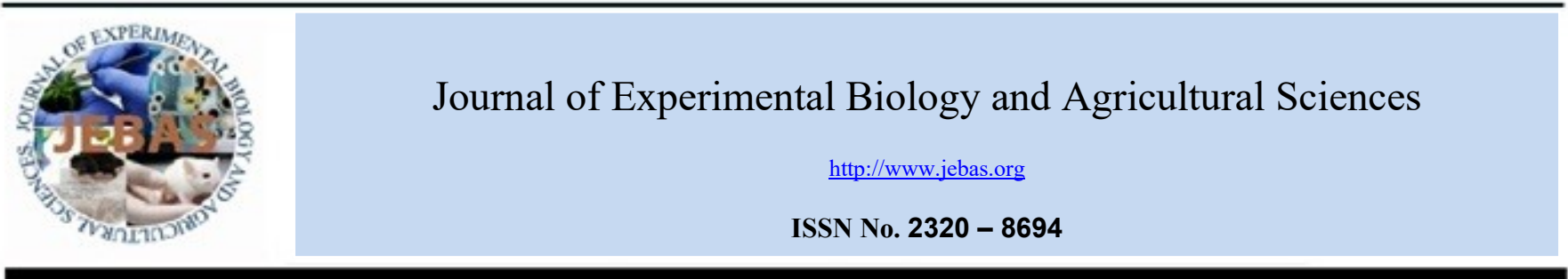

\title{
PROVENANCE VARIATIONS OF MORPHOMETRICTRAITS AND OIL CONTENTS OF Madhuca latifolia MACBRIDE IN ODISHA: IMPLICATION FOR TREE IMPROVEMENT
}

\author{
Saswat Nayak ${ }^{1,2}$, Uttam Kumar Sahoo ${ }^{1}$, Uttam Thangjam ${ }^{1}$, L. M. Garnayak ${ }^{3}$ \\ ${ }^{1}$ Department of Forestry, School of Earth Sciences \& Natural Resource Management, Mizoram University, Aizawl-796 004, India \\ ${ }^{2}$ College of Forestry, Odisha University of Agriculture and Technology, Bhubaneswar-751 001, India \\ 3 College of Agriculture, Odisha University of Agriculture and Technology, Bhubaneswar-751 001, India
}

Received -April 05, 2020; Revision - May 15, 2020; Accepted - June 02, 2020

Available Online - June 25, 2020

DOI: http://dx.doi.org/10.18006/2020.8(3).224.232

\section{KEYWORDS \\ Madhuca latifolia \\ Seed traits \\ Oil content \\ Coefficient of variation}

\begin{abstract}
Current study assessed the variability of fruit, seed trait and oil content of Madhuca latifolia Macbride from 10 different provenance of Odisha and compared these with climatic features. All fruits and seed traits were measured using a seed calliper; weight measured using a sensitive balance and oil extraction was done through Soxhlet apparatus. Coefficient of variation was calculated to determine the amount of variability between the morphometric traits and Pearson's correlation was performed between morphometric traits, oil characters and climatic factors. The findings of current study revealed significant variations $(\mathrm{P}<0.05)$ in all studied traits between the provenances. Increase in temperature was found strongly associated $(\mathrm{P}<0.01)$ with higher values of fruit width, thickness, fruit and seed weight. Further, relative humidity was also significantly $(\mathrm{P}<0.05)$ correlated with seed, kernel length and fruit weight. With increase altitude, value of fruit width, fruit weight and hilum length decreased while reverse was true for increase in latitude and longitude. Higher rainfall was associated with greater per cent of fatty acid and more iodine value. Among the provenances, P6 (Nabarangpur) ranked $1^{\text {st }}$ in all fruit, seed and oil traits and therefore result of study recommended the use of seeds from this source for oil extraction and commercial use, and for further tree improvement.
\end{abstract}

* Corresponding author

E-mail: uksahoo_2003@rediffmail.com; uttams64@gmail.com (Uttam Kumar Sahoo)

Peer review under responsibility of Journal of Experimental Biology and Agricultural Sciences.

Production and Hosting by Horizon Publisher India [HPI] (http://www.horizonpublisherindia.in/).

All rights reserved.
All the articles published by Journal of Experimental Biology and Agricultural Sciences are licensed under a Creative Commons Attribution-NonCommercial 4.0 International License Based on a work at www.jebas.org.

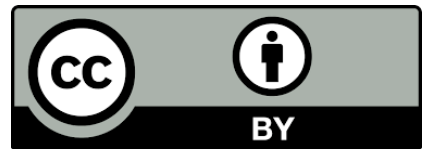




\section{Introduction}

Provenance studies in forest trees are very important as it helps in identifying the best and highly adaptable provenance. In fact forest tree improvement programme starts with the scanning of provenances/ seed source capable of providing best-adapted trees (Thangjam et al., 2020). Increase yield and resistance to disease can be achieved through the selection and use of seed from good provenance. Seed source studies are also desirable to screen the naturally available genetic variation to utilize the best material for maximum productivity and for further breeding programme (Ruotsalainen, 2014).

Madhuca latifolia Macbride (commonly known as 'Mahua') is one of the most important multipurpose trees in Central and Eastern India as it provides economic sustainability to tribal livelihoods (Nayak \& Sahoo, 2020a). Numerous use of this species includes flower and fruits as vegetables, seed oil for cooking, and therapeutic massages, fruit pulp for alcoholic fermentation. Mahua seeds containing 20 to $50 \%$ fatty oil which used as manufacture of soap and mahua oil seed cake as manure (Shivakumar et al., 2011). The species is reported to have good ecological (Nayak \& Sahoo, 2020b) and genetic diversity (Hedge et al., 2018; Nimbalkar et al., 2018) and therefore understanding geographic distribution of morphometric traits (tree traits, fruit/seed traits, oil content) in relation to climatic features will help in sourcing the material for not only tree improvement but for commercial/industrial use.

Seed oils serve as the primary energy source to the developing embryo during the heterotrophic stage (Pujar et al., 2006), prior to the initiation of photosynthesis. The quantity and quality of oils in seeds is crucial in determining plant fitness, germination success, emergence and establishment of a plant (Finch-Savage \& Bassel, 2016). Studies of the biogeographic distribution of seed oil content in plants are fundamental to understanding the mechanisms of adaptive evolution in plants as seed oil is the primary energy source needed for germination and establishment of plants. However, seed oil content as an adaptive trait in plants is poorly understood. Some studies have shown that the pattern of oil composition in seeds may be influenced by latitude and between species (Finch-Savage \& Bassel, 2016). Seed oils primarily accumulate neutral oils (Lersten et al., 2006) which are composed of triacyglycerols (TAGs). Seed germination and plant establishment in most plants depend on amount of stored seed energy and therefore studies on seed traits like seed size, weight and endosperm content may help in understanding the reproductive success of plants. Besides, study on seed oil content (total content and quality) which influence initial rapid growth in plants may help in understanding breeding significance of oil seed crops. However, there are scanty information pertaining to effect of seed source on oil content and quality and especially, in case of $M$. latifolia.
The objectives of this study were to evaluate (a) morphometric tree traits with regard to variation in tree height, $\mathrm{DBH}$, fruit, seed and oil across different provenances, (b) relate these variables with climatic features, and (c) to identify the best provenance with good oil yield potential for commercial use and for tree improvement.

\section{Materials and Methods}

\subsection{Sampling design}

Ten provenances were selected for this study (Figure 1) whose geocoordinates, altitude and climatic attributes are given in Table 1. Ten healthy, disease/pest-free and phenotypically superior trees (referred as candidate plus tree) were selected in each provenance for fruits/seed collection. Sampling was carried out in large stands which are shown to exhibit high rates of outcrossing. Within a provenance matured fruits were collected from trees spread at least $100 \mathrm{~m}$ apart, to avoid sampling from close relatives. From each tree, 3 random fruits samples (each containing 100 fresh, ripened) were collected during the month of May-June. These fruits were dried in shade for 10 days before seed extraction using secateurs. Fruits collected from different maternal trees were kept separate, to enable population trait variation within provenances for estimation of heritability.

\subsection{Measurement of morphometric traits and oil content}

Fruit, seed and kernel length were measured by a digital calliper. The length was measured along the longest axis while width measurement was taken at the widest face at the middle of the fruit/seed/kernel. Weight measurement was carried out using a sensitive balance. Seeds were dried in hot air oven and de-shelled manually to obtain kernel. Kernels were crushed and fine grounded. Oil was extracted from the powered sample of known weight in Soxhlet extraction apparatus using petroleum ether $\left(60^{\circ} \mathrm{C}-80^{\circ} \mathrm{C}\right)$ for six hours without interruption by gently heating it. Ether was evaporated on a water bath until no odour of ether remained. The extracted oil was measured for percentage of oil content, specific gravity, acid value, free fatty acid (\%), saponification value and iodine value of the extracted oil was determined using the method as prescribed in AOAC (1970)

\subsection{Data Analysis}

General Linear Model procedure of statistica software was employed for analysis of variance (One way) to differentiate between various morphometric tree, seed traits and oil characters among the provenances while coefficient of variation $(\mathrm{CV})$ was performed to determine the amount of variability in all these traits between the provenances. Besides, Pearson's correlation was carried out within and among the morphological characters, oil characters, germination and seedling characters, ecological, edaphic and climatic factors of the different provenances. 


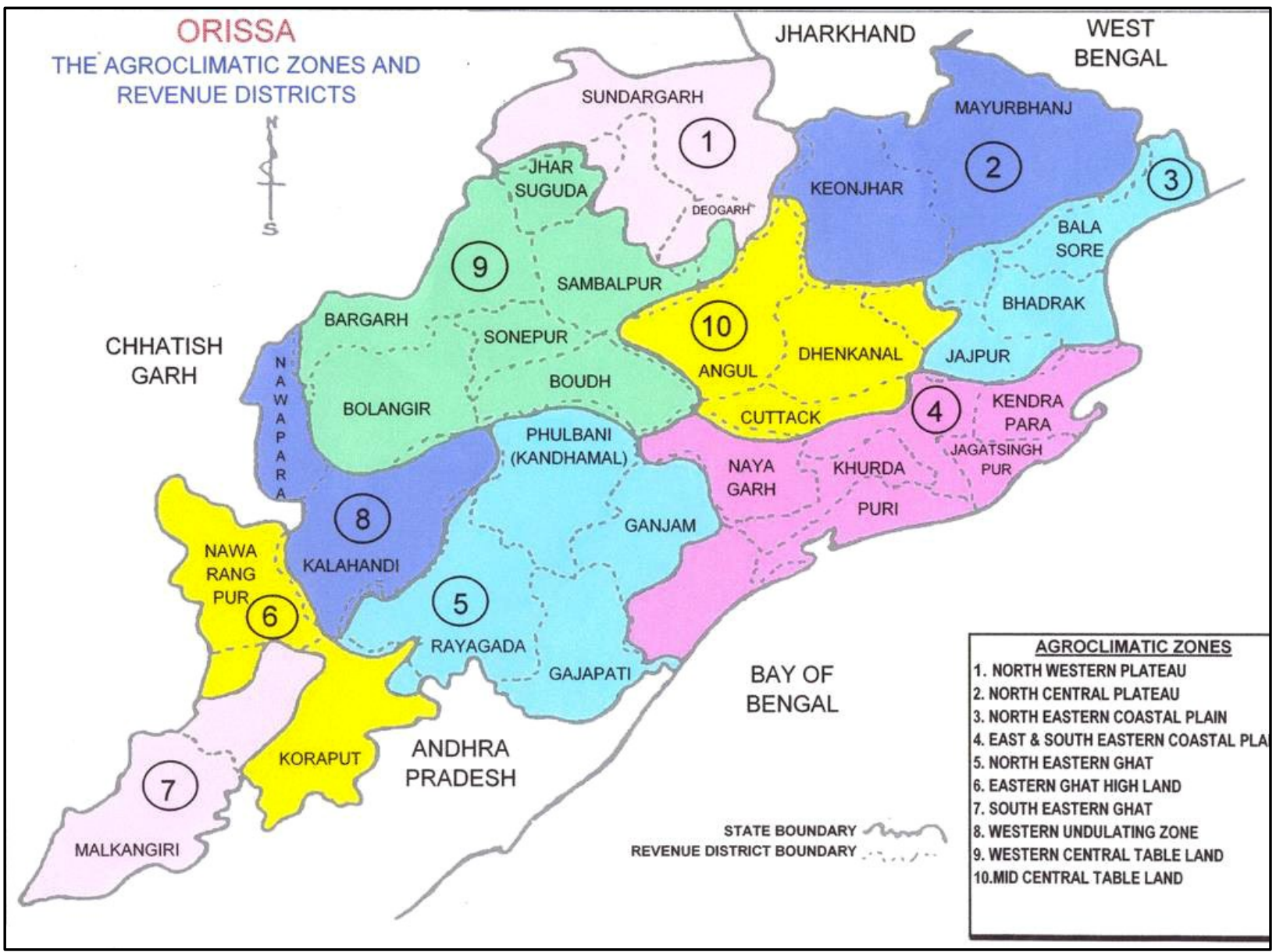

Figure 1. Map of Odisha showing ten provenances/study sites

Table 1Characteristics of provenance

\begin{tabular}{|ccccccccc|}
\hline Provenance & Forest division & $\begin{array}{c}\text { Latitude } \\
(\text { decimal })\end{array}$ & $\begin{array}{c}\text { Longitude } \\
(\text { decimal })\end{array}$ & Altitude $(\mathrm{m})$ & $\begin{array}{c}\text { MAR } \\
(\mathrm{mm})\end{array}$ & $\begin{array}{c}\text { Humidity } \\
(\%)\end{array}$ & $\begin{array}{c}\text { MAT } \\
\left({ }^{\circ} \mathrm{C}\right)\end{array}$ \\
\hline P1 & Sundargarh & $21.973^{\circ}$ & $83.61^{\circ}$ & 282.32 & 1183.9 & 51.2 & 27.4 \\
\hline P2 & Mayurbhanj & $22.135^{\circ}$ & $86.448^{\circ}$ & 74.61 & 1358.9 & 61.6 & 26.8 \\
\hline P3 & Balasore & $21.489^{\circ}$ & $86.672^{\circ}$ & 83.65 & 1600.1 & 1077.8 & 64.3 & 28 \\
\hline P4 & Nayagarh & $20.363^{\circ}$ & $84.78^{\circ}$ & 146.92 & 1232.4 & 53.1 & 28 \\
\hline P5 & Kandhamal & $20.145^{\circ}$ & $84.207^{\circ}$ & 592.35 & 1480.7 & 61.6 & 26.8 \\
\hline P6 & Nabarangpur & $19.534^{\circ}$ & $82.467^{\circ}$ & 612.62 & 1514.3 & 58.3 & 25.3 \\
\hline P7 & Malkangiri & $18.779^{\circ}$ & $82.538^{\circ}$ & 575.22 & 894.7 & 57.2 & 24.3 \\
\hline P8 & Nuapada & $20.74^{\circ}$ & $82.545^{\circ}$ & 387.63 & 1136.8 & 53.1 & 27.8 \\
\hline P9 & Bolangir & $20.705^{\circ}$ & $82.944^{\circ}$ & 297.00 & 1172.3 & 61.8 & 27.4 \\
\hline P10 & Angul & $20.873^{\circ}$ & $84.46^{\circ}$ & 46.25 & & 26 \\
\hline
\end{tabular}

MAR-Mean annual rainfall, MAT-Mean annual temperature 
Finally, relative performances of each provenance were determined for fruit and seed characters and physico-chemical characters of the seeds.Not all characters have equal importance; therefore, weights were calculated from the correlation analysis between each group characters with physico-chemical properties. The results that showed significant correlation $\mathrm{P}<0.01$ and $\mathrm{P}<0.05$ assigned " 1 " and " 0.5 " respectively while those did not show significant relationship were assigned " 0.05 " for scoring purpose. The aggregate score of each character were used to calculate maximum weight of the same character. However, for the five physicochemical characters same weights were assigned as they have equal importance. These weights were then used to determine the overall rank of each provenance. All the analysis was done using IBM SPSS 20 software.

\section{Results}

\subsection{Reproductive traits}

Significant variations $(\mathrm{P}<0.05)$ in morphometric characters in fruit, seed and oil were observed between the provenances (Table 2). Fruit length varied from $3.98 \mathrm{~cm}(\mathrm{P} 9)$ to $5.32 \mathrm{~cm}(\mathrm{P} 1)$, fruit width from $2.22 \mathrm{~cm}(\mathrm{P} 7)$ to $2.97 \mathrm{~cm}(\mathrm{P} 2), 100$ fruit weight from $855.77 \mathrm{~g}$ (P7) to $1711.39 \mathrm{~g}(\mathrm{P} 10)$; seed length from $3.01 \mathrm{~cm}$ (P9) to $3.47 \mathrm{~cm}$ (P2), seed width from $1.36 \mathrm{~cm}(\mathrm{P} 7)$ to $177 \mathrm{~cm}$ (P5), 100 seed weight from $2.63 \mathrm{~g}$ (P9) to $3.05 \mathrm{~g}$ (P2) and oil content from $39.14 \%$ (P1) to $43.25 \%(\mathrm{P} 2)$. There were discernable variations in all these parameters within and between the provenances, the variations were more pronounced between the provenances than within a provenance. Among the provenances, variability among fruit characters was highest for fruit weight (FWT) $(\mathrm{CV}=24.28)$ followed by fruit length (FL) $(\mathrm{CV}=14.14)$ and least in fruit thickness (FT) $(\mathrm{CV}=10.28)$. Among the seed and kernel traits highest variation was found in kernel weight $(\mathrm{KWT})(\mathrm{CV}=19.94)$ and seed weight (SWT) $(\mathrm{CV}=17.45)$, and lowest in seed width $(\mathrm{SW})(\mathrm{CV}=8.20)$ and kernel width $(\mathrm{KW})(\mathrm{CV}=8.94)$. Significant correlations were found between climatic and geographic variables on fruit and seed characters (Table 4). Increased in temperature was associated with higher values of fruit width, fruit thickness, fruit weight, seed weight and hilum length while precipitation had no significant association any of the fruit and seed characters. Relative humidity was significantly $(\mathrm{P}<0.05)$ correlated positively with seed length, kernel length and fruit weight. With increase in altitude the value of fruit width, fruit weight and hilum length decreased while reverse was true for increase latitude and longitude in the present study (Table 3). The study also found significant correlation among all the fruit and seed characters with little exception (Table 4). Among fruit characters, fruit length had no significant association with fruit thickness. Similarly among seed characters correlation was not significant between seed length with seed thickness and kernel thickness; hilum length with seed thickness and kernel thickness. However, kernel length had no significant correlation with kernel thickness and kernel weight.

\subsection{Oil characters}

Variations between provenances were found significant $(\mathrm{P}<0.001)$ for all the physico-chemical parameters except oil content (OC) $(\mathrm{P}=0.34)$ (Table 1). Oil content varied from $39.14 \%$ (P1) to $43.25 \%(\mathrm{P} 2)$ while saponification value varies from $130.92(\mathrm{P} 7)$ to 204.53 (P1), free fatty acid from 0.59 (P9) to 4.51 (P1), iodine value from $55.42(\mathrm{P} 8)$ to $64.52(\mathrm{P} 7)$, specific gravity from 0.872 (P7) to 0.9 (P8) (Table 1). Some of the geo-climatic parameters also affected seed oil characters. Higher amount of rainfall were associated with greater percentage of free fatty acid and more iodine value. However, saponification value was found to decrease with increase in rainfall. Positive value of correlation was also observed between per cent free fatty acid and altitude. Higher latitude was found suitable for getting higher iodine value (Table 5). Pearson correlation analysis found significant relation between saponification value, specific gravity and iodine value. A direct and proportional relationship was found between specific gravity and saponification value while reciprocal relationship was observed between iodine value with saponification value and specific gravity (Table 6). These oil characters also exhibited some degree of influence on fruit and seed traits. Saponification value and iodine value had significant $(\mathrm{P}<0.05)$ relation with all fruit and seed traits, however, the difference was that while saponification value had positive correlation iodine value had negative correlation with the fruit and seed traits. Higher concentration of free fatty acid was associated with fruit and seed thickness. Similarly, seed and kernel thickness were also correlated with the value of specific gravity (Table 7).

\subsection{Best provenance}

The two categories grouped to rank the best performing provenance were fruit and seed characters, and physic-chemical characters of seed oil (Table 8). Pair wise ranking were carried out to find the best performing provenance per category. For fruit and seed characters P6 gave the highest rank followed by P10 and least in P5. P6 was also ranked highest for physico-chemical characters followed by $\mathrm{P} 1$ and least in $\mathrm{P} 9$.

\section{Discussion}

All provenances showed significant differences in fruit, seed morphometric traits within and among provenances. This reflects an overriding influence of both genetic and environmental variation. The variation in morphometric fruit and seed traits within and between plant species are resultant of evolutionary responses of plant to maximize the potential fitness by producing larger number of seeds (Elmagboul et al., 2014; Finch-Savage \& 


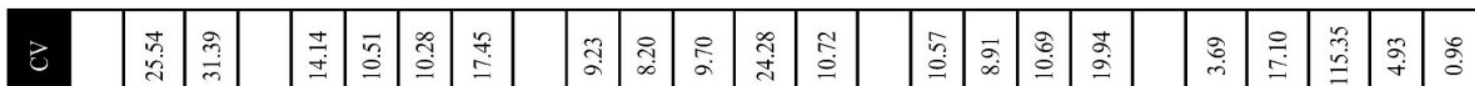

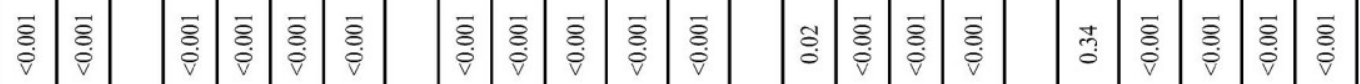

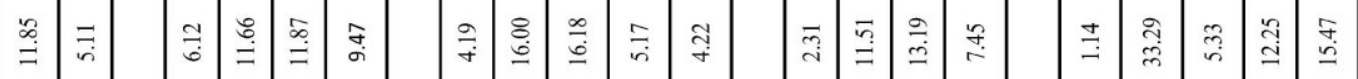

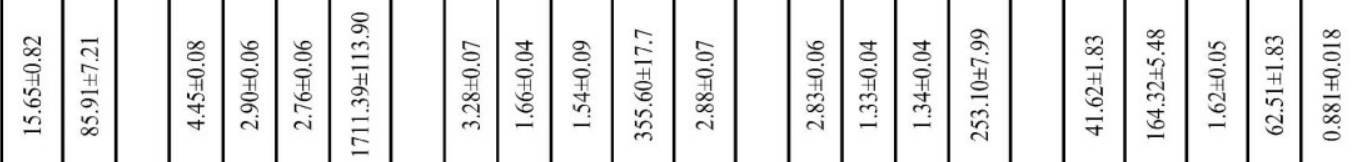

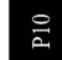

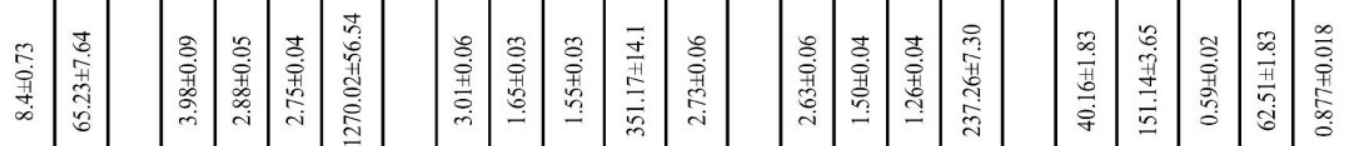

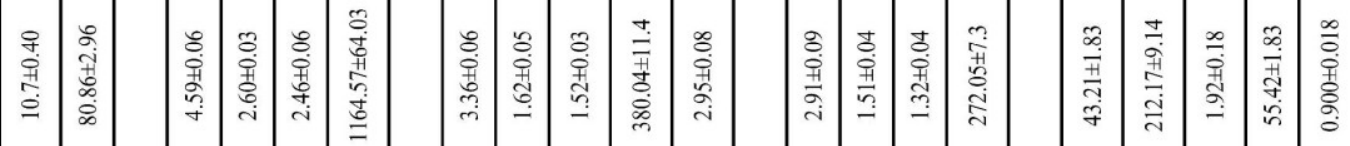

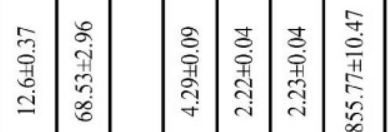

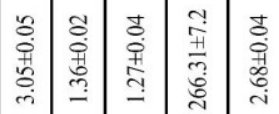

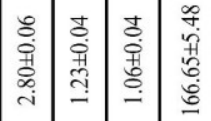

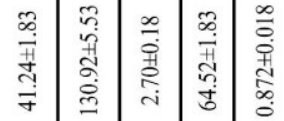

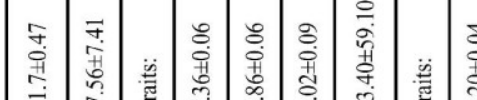

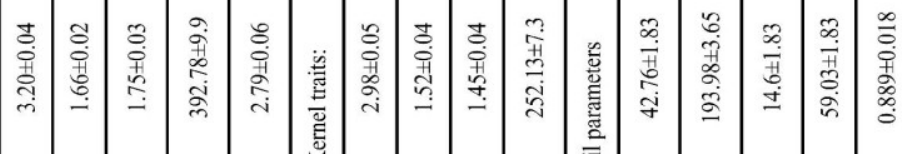
量

击

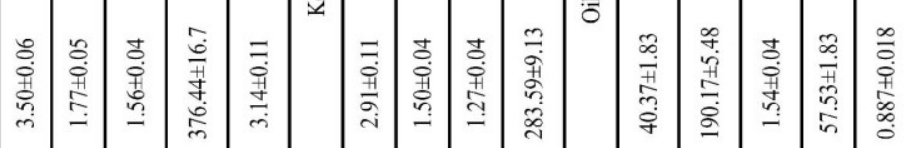

空

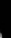

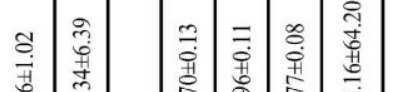

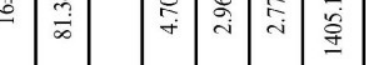

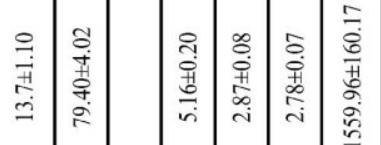

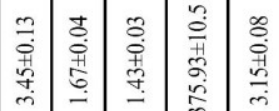

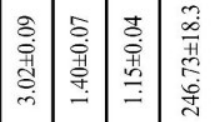

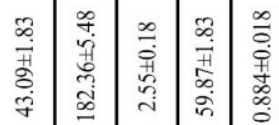

章

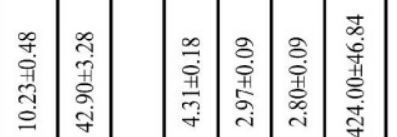

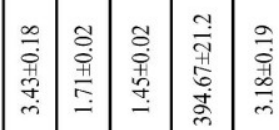

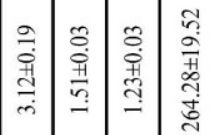

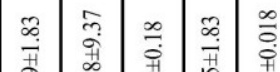

-7 更

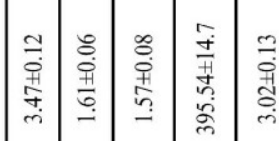

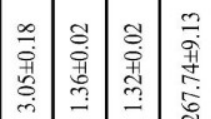

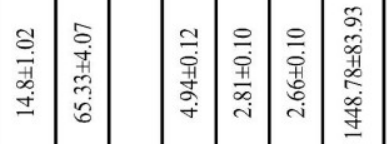

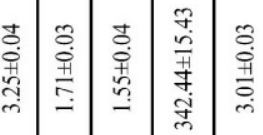

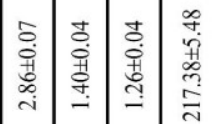

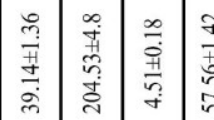

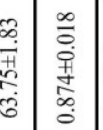

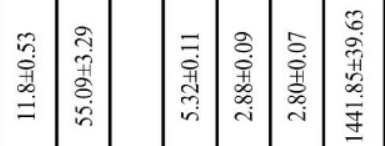

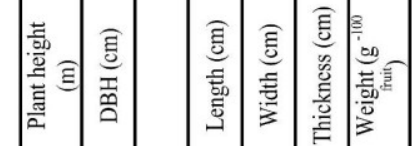

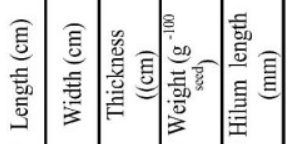

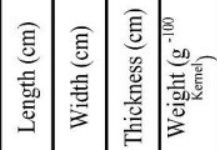

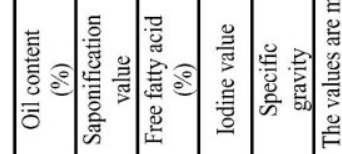

Journal of Experimental Biology and Agricultural Sciences

http://www.jebas.org 
Table3 Correlation between fruit and seed characters with geographic characters

\begin{tabular}{|c|c|c|c|c|c|c|}
\hline & TEMP & RF & RH & ALT & LON & LAT \\
\hline $\mathrm{FL}$ & 0.08 & -0.195 & 0.003 & -0.153 & 0.177 & $.273 * *$ \\
\hline FW & $.587 * *$ & -0.071 & 0.039 & $-.300 * *$ & $.346 * *$ & $.414 * *$ \\
\hline FT & $.530 * *$ & 0.051 & 0.095 & -0.121 & 0.169 & $.229 *$ \\
\hline SL & 0.123 & -0.058 & $.200 *$ & -0.191 & $.387 * *$ & $.234^{*}$ \\
\hline SW & $.508 * *$ & -0.195 & -0.074 & -0.19 & $.275 * *$ & $.408 * *$ \\
\hline ST & 0.168 & -0.065 & -0.092 & 0.092 & -0.058 & 0.194 \\
\hline HL & $.243^{*}$ & -0.045 & 0.143 & $-.226^{*}$ & $.403 * *$ & $.278 * *$ \\
\hline FWT & $.437 * *$ & -0.045 & $.251 *$ & $-.298 * *$ & $.266 * *$ & $.270 * *$ \\
\hline SWT & 0.19 & -0.071 & 0.193 & -0.188 & $.278 * *$ & $.298 * *$ \\
\hline KL & .049 & .149 & $.289^{* *}$ & -.133 & $.290^{* *}$ & .121 \\
\hline KT & .013 & -.092 & -.015 & .009 & -.044 & $.203^{*}$ \\
\hline KW & .153 & -.132 & -.102 & .106 & -.027 & .128 \\
\hline KWT & .161 & -.182 & .108 & -.160 & $.273^{* *}$ & $.284^{* *}$ \\
\hline
\end{tabular}

FL-fruit length, FW-fruit width, FT-fruit thickness, SL-seed length, SW-seed width, ST-seed thickness, HL-hilum length,

FWT-fruit weight, SWT-seed weight, KL-kernel length, KT-kernel thickness, KW-kernel width, KWL-kernel weight,

Temp-temperature, RF-rainfall, RH-relative humidity, Alt-altitude, Lon-longitude, Lat-latitude, ${ }^{*},{ }^{* *}$ significant at

$\mathrm{P}<0.5,0.01$ respectively.

Table 4 Correlation among fruit and seed characters

\begin{tabular}{|c|c|c|c|c|c|c|c|c|c|c|c|c|c|}
\hline & FL & FW & FT & SL & SW & ST & HL & FWT & SWT & KL & KT & KW & KWT \\
\hline FL & 1 & & & & & & & & & & & & \\
\hline FW & $.20 *$ & 1 & & & & & & & & & & & \\
\hline FT & 0.145 & $.876 * *$ & 1 & & & & & & & & & & \\
\hline SL & $.669 * *$ & $.285^{* *}$ & $.200 *$ & 1 & & & & & & & & & \\
\hline SW & 0.196 & $.773 * *$ & $.668 * *$ & $.371^{* *}$ & 1 & & & & & & & & \\
\hline ST & -0.007 & $.522 * *$ & $.626^{* *}$ & 0.086 & $.566 * *$ & 1 & & & & & & & \\
\hline HL & $.667 * *$ & $.302 * *$ & $.212 *$ & $.932 * *$ & $.371 * *$ & -0.004 & 1 & & & & & & \\
\hline FWT & $.401 * *$ & $.798 * *$ & $.778^{* *}$ & $.380 * *$ & $.590 * *$ & $.501 * *$ & $.350 * *$ & 1 & & & & & \\
\hline SWT & $.320 * *$ & $.615^{* * *}$ & $.527 * *$ & $.614^{* *}$ & $.662 * *$ & $.569^{* *}$ & $.516^{* *}$ & $.556^{* *}$ & 1 & & & & \\
\hline KL & $.555^{* *}$ & $.210^{*}$ & 0.194 & $.800^{* *}$ & $.227^{*}$ & 0.018 & $.735^{* *}$ & $.329 * *$ & $.473 * *$ & 1 & & & \\
\hline KT & 0.009 & $.454 * *$ & $.527 * *$ & 0.118 & $.492 * *$ & $.863^{* *}$ & -0.008 & $.514 * *$ & $.532 * *$ & 0.076 & 1 & & \\
\hline KW & -0.01 & $.571 * *$ & $.525^{* *}$ & $.229 *$ & $.718^{* *}$ & $.619^{* *}$ & $.203^{*}$ & $.341 * *$ & $.640 * *$ & 0.11 & $.558^{* *}$ & 1 & \\
\hline KWT & $.255^{*}$ & $.609 * *$ & $.464 * *$ & $.609 * *$ & $.695 * *$ & $.528^{* *}$ & $.490 * *$ & $.513 * *$ & $.938 * *$ & $.436^{* *}$ & $.533^{* *}$ & $.645^{* *}$ & 1 \\
\hline
\end{tabular}

FL-fruit length, FW-fruit width, FT-fruit thickness, SL-seed length, SW-seed width, ST-seed thickness, HL-hilum length, FWT-fruit weight, SWT-seed weight, KL-kernel length, KT-kernel thickness, KW-kernel width, KWL-kernel weight, *, ** significant at $\mathrm{P}<0.5,0.01$ respectively 
Table 5Correlation between physico-chemical properties of seeds and geographic characters

\begin{tabular}{|cccccccc|}
\hline & TEMP & RF & RH & ALT & LON & LAT \\
\hline OC & -.142 & -.071 & .190 & .001 & -.001 & -.052 & .105 \\
\hline SPV & .012 & $-.293^{* *}$ & -.114 & .146 & -.149 & -.190 & .180 \\
\hline FFA $\%$ & -.035 & $.227^{*}$ & .105 & $.262^{* *}$ & -.088 & .118 & $.251^{*}$ \\
\hline SG & -.105 & -.113 & .013 & -.151 & .107 & -.131 \\
\hline IV & .058 & $.316^{* *}$ & .161 & -190 \\
\hline
\end{tabular}

OC-oil content, SPV-saponification value, FFA-free fatty acid, SG-specific gravity, IV-iodine value, Temp-temperature,

RF-rainfall, RH-relative humidity, Alt-altitude, Lon-longitude, Lat-latitude, *, ** significant at $\mathrm{P}<0.5,0.01$ respectively.

Table6.Correlation within physico-chemical properties of seeds

\begin{tabular}{|ccccc|c|}
\hline & OC & SPV & FFA $\%$ & SG & \\
\hline OC & 1 & & & & \\
\hline SPV & .070 & 1 & 1 & 1 & \\
\hline FFA $\%$ & .143 & .150 & $.291^{* *}$ & .054 & $-.390^{* *}$ \\
\hline SG & -.011 & $-.944^{* *}$ & -.078 & 1 \\
\hline IV & -.111 &
\end{tabular}

OC-oil content, SPV-saponification value, FFA-free fatty acid, SG-specific gravity, IV-iodine value,

** significant at $\mathrm{P}<0.01$.

Table7.Correlation between fruit and seed characters with physico-chemical properties of seeds

\begin{tabular}{|c|c|c|c|c|c|}
\hline & $\mathrm{OC}$ & SPV & FFA $\%$ & SG & IV \\
\hline FL & -0.013 & 0.158 & -0.049 & 0.122 & -0.149 \\
\hline FW & 0.061 & $.304 * *$ & 0.019 & 0.039 & $-.298^{* *}$ \\
\hline FT & 0.079 & $.280 * *$ & $.238^{*}$ & -0.017 & $-.203 *$ \\
\hline $\mathrm{SL}$ & 0.008 & 0.152 & -0.108 & 0.132 & -0.186 \\
\hline SW & -0.062 & $.433 * *$ & -0.005 & 0.090 & $-.419 * *$ \\
\hline ST & 0.122 & $.269 * *$ & $.351 * *$ & $.228 *$ & $-.260 * *$ \\
\hline HL & -0.087 & $.211 *$ & -0.151 & 0.114 & $-.209^{*}$ \\
\hline FWT & 0.100 & $.245^{*}$ & 0.172 & 0.089 & $-.228 *$ \\
\hline SWT & 0.169 & $.216^{*}$ & 0.058 & 0.159 & $-.241 *$ \\
\hline $\mathrm{KL}$ & -0.113 & 0.059 & 0.043 & 0.056 & -0.063 \\
\hline $\mathrm{KT}$ & 0.16 & $.248 *$ & $.303 * *$ & $.290 * *$ & $-.271 * *$ \\
\hline KW & 0.062 & $.421 * *$ & 0.07 & 0.160 & $-.422 * *$ \\
\hline KWT & 0.125 & $.216^{*}$ & -0.03 & 0.154 & $-.263 * *$ \\
\hline
\end{tabular}

FL-fruit length, FW-fruit width, FT-fruit thickness, SL-seed length, SW-seed width, ST-seed thickness,

HL-hilum length, FWT-fruit weight, SWT-seed weight, KL-kernel length, KT-kernel thickness, KW-kernel width,

KWL-kernel weight, OC-oil content, SPV-saponification value, FFA-free fatty acid, SG-specific gravity,

IV-iodine value, * ** significant at $\mathrm{P}<0.5,0.01$ respectively.

Table 8 Best provenance for various attributes based on cumulative rank

\begin{tabular}{|ccccccccccc|}
\hline & P1 & P2 & P3 & P4 & P5 & P6 & P7 & P8 & P9 & P10 \\
\hline Fruit and seed characters & 7 & 5 & 4 & 6 & 3 & 1 & 10 & 9 & 8 & 2 \\
\hline Physico-chemical properties of oil & 2 & 8 & 5 & 4 & 6 & 1 & 9 & 3 & 10 & 7 \\
\hline
\end{tabular}

1-best, 10-poorest (in 10 point scale)

Journal of Experimental Biology and Agricultural Sciences

http://www.jebas.org 
Bassel, 2016) and this may increase chance of establishment of resulting seedlings through greater allocation of maternal resources to individual seeds. According to Takuathung et al. (2012) the variability in fruit/seed size may be a consequence of compromise between requirements for dispersal (which favour small seeds) and the requirements for seedling establishment (which favour large seeds). A wide ecological range of the species nevertheless confirm high pattern of variation among and within location, which may be either due to genetic character of the source population (LaraRomero et al., 2014; Finch-Savage \& Bassel, 2016) or the impact of mother plant (Singh et al., 2010). Higher value of CV was found in 100 fruit weight (24\%), seed weight (24\%), kernel weight $(19 \%)$, saponification value (17\%) and fruit length (14\%). Previous studies carried also suggested that Madhuca longifolia exhibits provenance variations in fruit length, fruit weight, kernel width and kernel thickness (Abraham et al., 2010;Wani \& Ahmad, 2013) and oil content (Hedge et al., 2018). In current study, kernel oil percent ranged from $39.14 \%(\mathrm{P} 1)$ to $43.25 \%(\mathrm{P} 2)$; results are in agreement with the finding of Divakar \& Das (2014) those who reported 38.3$50.2 \%$ variation in kernel oil percent in Jharkhand. Kernel oil percent reported in this study are lesser than the value (44.4-61.5\%) reported by Sangita Yadav et al. (2011) from Tamil Nadu. The variation in oil content and its other parameters between the provenances could be resultant of microclimatic and geographic variation within each zones on its genotypes. Mehedi et al. (2014) described that microgeographic and micro habitat conditions can be a reason for variation in oil content. Correlation between fruit, seed and oil characters with variation in temperature, rainfall and other geographic coordinates is important as these factors play a crucial role on the overall seed characters during seed development and eventually seedling growth. Warmer temperature, higher latitude and higher longitude were associated with better quality and quantity of fruits and seeds. However, since temperature have dissenting effect on altitude, a higher altitude was found correlated to lower value on the reproductive characters of this tree seeds. Similar observation was reported in trees of Cordia africana (Loha et al., 2006) and Parkia timoriana (Thangjam et al., 2020). Unlike reproductive characters, oil physico-chemical characters showed significant correlation with rainfall and non- significance relationship with temperature. In present study seeds collected from wet regions are associated with greater concentration of free fatty acid and iodine value. The seeds drawn from higher altitude too showed better free fatty acid and higher latitude for specific gravity or density. In contrast Munasinghe \& Wansapala (2015) reported highest oil yield in Madhuca longifolia in dry zone (1000-1500 mm rainfall) than mild-wet zone (1500-2000 mm rainfall) in Sri Lanka while the oil content reported was within the range (50.07-53.85\%) of our study. The fatty acid biosynthesis pathway are linked to physiological processes of plants which are somewhat regulated by genotype environment interaction during seed development (Munasinghe \& Wansapala, 2015).

\section{Conclusion}

The results of the present study suggest that Nabarangpur (P6) is the best provenance for fruit and seed traits, oil characters. The extent of variability observed in CPTs across various provenances further offer strategies for tree breeders and for potential oil yield for industrial use.

\section{Acknowledgments}

First author (SN) wishes to thank the Vice Chancellor, Orissa University of Agriculture and Technology, Bhubaneswar for providing logistic support to carry out the experiment. The Indian Meteorological Department (IMD) and Centre for Disaster Management (CDM) of Odisha provided the required climatic data that are used in this paper.

\section{Conflict of interest}

The authors declare that they have no conflict of interest arising out of this study

\section{References}

Abraham Z, SangitaYadav S, Latha M, Mani M, Mishra SK (2010) Seed variability in Madhuca longifolia (Koenig) J.F. Macbride, a source of oil for use as bio-energy. Genetic Resources and Crop Evolution 57: 619-623. https://doi.org/10.1016/j.biombioe.2011.01.010.

AOAC (1970) Official method of analysis XI Edn. Association of official analytical chemists, Washington D. C.

Divakar BN, Das M (2014) Relationship of seed traits on initial progency growth performance and divergence studies in Madhuca latifolia Macb. for further use in tree improvement. Journal of Tropical Forest and Environment $4: 11-23$.

Elmagboul H, Mahgoup S, Eldoma A (2014) Variation in seed morphometric characteristic and germination of Acacia tortilis subspecies raddiana and subspecies spirocarpa among three provenances in Sudan. Global Journal of Bio-Science and Biotechnology 3 : 191-196.

Finch-Savage WE, Bassel GW (2016) Seed vigour and crop establishment: extending performance beyond adaptation. Journal of Experimental Botany 67(3): 567-591. https://doi.org/10.1093/jxb/erv490

Hedge HT, Gunaga RP, Thakur NS (2018) Variation in oil content among 13 populations of Mahua (Madhuca longifolia var. latifolia (Roxb.) A Chev.) in Gujarat. International Journal of Chemical Studies 6(5): 35-38. 
Lara-Romero C, Rovledo-Arnucio JJ, Garcia-Fernandez A, Iriondo JM (2014) Assessing intraspecific variation in effective dispersal along an altitudinal gradient: A test in two Mediterranean highmountain plants. PLos One 9(1): e87189. https://doi.org/10.1371/journal.pone.0087189

Lersten NR, Czlapinski AR, Curtis JD, Freckmann R, Horner HT (2006) Oil bodies in leaf mesophyll cells of angiosperms: overview and a selected survey. American Journal of Botany 93: 1731-1739.

Loha A, Tigabu M, Teketay D, Tundkvist K Fries A (2006) Provenance variation in seed morphometric traits, germination and seedling growth of Cordia africana Lam. New Forests 32(1): 71-86.

Mehdi TS, Gity SI, Narjes A (2014) Inter and Intrapopulation variations in StachysinflataBenth.based on phenotype plasticity (an ecological and phytogeographicalreview). International Research Journal of Biological Sciences 3(2):9-20.

Munasinghe M, Wansapala J (2015) Study on variation in seed morphology, oil content and fatty acid profile of Madhuca longifolia grown in different agro-climatic zones of Sri Lanka. Science $\quad$ Research $\quad 3(3)$ : 109.https://doi.org/10.11648/5.sr.20150303.20

Nayak S, Sahoo UK (2020a) Contribution of Mahua (Madhuca latifolia Mac.) to household economy in Odisha. Environment and Ecology 38(2): 204-207

Nayak S, Sahoo UK (2020b) Tree diversity and ecological status of Madhuca latifolia (Roxb.) J.F Macrb in forests of Odisha. Indian Journal of Ecology 47(1): 138-149.

Nimbalkar SD, Jade SS, Bahulikar RA (2018). Genetic diversity in the candidate trees of Madhuca indica J.F. Gmel revealed by intersimple sequence repeats (ISSRs). 3 Biotechology 8(3): 143.https://doi.org/ 10.1007/s13205-018-1168-4.

Pujar A, Jaiswal P, Kellog EA, Ilic K, Vincent L, Ayuraham S, Stevens P, Zopata F, Reiser L, Rhee S, Sachs MM, Schaeffer M,
Stein L, Ware D, McCouch S (2006) Whole plant growth stage ontology for angiosperms and its application in plant biology. Plant Physiology 142(4): 414-428.

https://doi.org/10.1104/pp.106.085720

SangitaYadav S, Suneja P, Hussain Z, Abraham Z, Mishra SK (2011) Genetic variability and divergence studies in seed and oil parameters of mahua (Madhuca longifolia Koenig) J.F. Macribide accessions. Biomass and Bioenergy 35(5): 17731778. https://doi.org/10.1016/j.biombioe.2011.01.010

Ruotsalainen S (2014) Increased forest production through forest tree breeding. Scandinavian Journal of Forest Research 29(4): 333344. https://doi.org/10.1080/02827581.2014.926100

Shivakumar BC, Girish AC, Gowda B, Vijaykumar GC, Mallikarjuna AP, Gowda APM, Thimmergowda MN (2011) Influence of pongamia, mahua and neem cakes on finger millet productivity and soil fertility. Journal of Applied and Natural Science 3(2): 274-276.

Singh B, P Saklani KP, Bhatt BP (2010) Provenance variation in seed and seedling attributes of Quercus glauca Thunb. inGarhwal Himalaya, India. Dendrobiology 63: 59-63.

Takuathung CN, D Pipatwattanakul D, Bhumibhamon S (2012) Provenance variation in seed morphometric traits and growth performance of Sennasiamea (Lam.) Erwin et Barneby at Lad. Kasetsart Journal of Natural Science 46: 394-407. URL : http://kasetsartjournal.ku.ac.th/

Thangjam U, Sahoo UK, Thong P (2020) Characterization of morphometric,reproductive and seedling traits of Parkia timoriana in northeast India. Silva Fennica 54(1): 10163.https://doi.org/10.14214/sf.10163

Wani MS, Ahmad L (2013) Estimation of field environment variability for germination and seedling traits in Madhuca indica Gmel. American Journal of Experimental Agriculture 3(2): 361-373. 